\title{
Analysis of virulence factors of Helicobacter pylori isolated from a Vietnamese population
}

Tomohisa Uchida ${ }^{1,2}$, Lam Tung Nguyen ${ }^{1,3}$, Akiko Takayama1,3, Tadayoshi Okimoto ${ }^{3}$, Masaaki Kodama ${ }^{3}$, Kazunari Murakami3, Takeshi Matsuhisa ${ }^{4}$, Tuan Dung Trinh ${ }^{5}$, Long Ta ${ }^{6}$, Dang Quy Dung Ho ${ }^{7}$, Hoa Hai Hoang8, Tetsuko Kishida ${ }^{2}$, Toshio Fujioka ${ }^{3}$, Masatsugu Moriyama ${ }^{1}$ and Yoshio Yamaoka*9,10

Address: ${ }^{1}$ Department of Molecular Pathology, Oita University Faculty of Medicine, Yufu, Japan, ${ }^{2}$ Department of Forensic Medicine, Oita University Faculty of Medicine, Yufu, Japan, ${ }^{3}$ Department of Gastroenterology, Oita University Faculty of Medicine, Yufu, Japan, ${ }^{4}$ Department of Gastrointestinal Endoscopy, Tama-Nagayama Hospital, Nippon Medical School, Tokyo, Japan, ${ }^{5}$ Department of Pathology, Hospital 108, Hanoi, Vietnam, ${ }^{6}$ Department of Hepato-Gastroenterology, Hospital 108, Hanoi, Vietnam, ${ }^{7}$ Department of Endoscopy, Cho Ray Hospital, Ho Chi Minh, Vietnam, ${ }^{8}$ Training and Researches Department, Cho Ray Hospital, Ho Chi Minh, Vietnam, ${ }^{9}$ Department of Medicine-Gastroenterology, Michael E. DeBakey Veterans Affairs Medical Center and Baylor College of Medicine, Houston, Texas, USA and ${ }^{10}$ Department of Environmental and Preventive Medicine, Oita University Faculty of Medicine, Yufu, Japan

Email: Tomohisa Uchida - tomohisa@med.oita-u.ac.jp; Lam Tung Nguyen - ngltung@med.oita-u.ac.jp; Akiko Takayama - a-taka@med.oitau.ac.jp; Tadayoshi Okimoto - okimoto@med.oita-u.ac.jp; Masaaki Kodama - kodm@med.oita-u.ac.jp;

Kazunari Murakami - murakam@med.oita-u.ac.jp; Takeshi Matsuhisa - matuhisa@m8.dion.ne.jp; Tuan Dung Trinh - quydung@gmail.com; Long Ta - taLong@viettel.vn; Dang Quy Dung Ho - dung108@viettel.vn; Hoa Hai Hoang - cdtbvcr@hcm.vnn.vn;

Tetsuko Kishida - kishida@med.oita-u.ac.jp; Toshio Fujioka - fujioka@med.oita-u.ac.jp; Masatsugu Moriyama - mmoriyam@med.oita-u.ac.jp; Yoshio Yamaoka* - yyamaoka@bcm.tmc.edu

* Corresponding author

Published: 23 August 2009

BMC Microbiology 2009, 9:175 doi:10.1 186/147/-2/80-9-175
Received: 12 March 2009

Accepted: 23 August 2009

This article is available from: http://www.biomedcentral.com/I47I-2180/9//75

(C) 2009 Uchida et al; licensee BioMed Central Ltd.

This is an Open Access article distributed under the terms of the Creative Commons Attribution License (http://creativecommons.org/licenses/by/2.0), which permits unrestricted use, distribution, and reproduction in any medium, provided the original work is properly cited.

\begin{abstract}
Background: The incidence of gastric cancer differs among countries in Asia, and it has been suggested that virulence factors associated with Helicobacter pylori are partly responsible. The aim of this study was to investigate several genetic factors regarded as virulence or molecular epidemiologic markers in $H$. pylori isolates from Vietnamese subjects.

Results: The cagA, vacA and cag right-end junction genotypes of $103 \mathrm{H}$. pylori strains from Vietnam $(54$ from Hanoi and 49 from Ho Chi Minh) were determined by PCR and sequencing. Three types of deletion in the region located upstream of the cagA Glu-Pro-Ile-Tyr-Ala (EPIYA) repeat region were identified: the 39-bp deletion type, the I8bp deletion type, and the no-deletion type. The majority of strains studied $(77 \% ; 80 / 103)$ had the I8-bp deletion irrespective of geographical location in the country or clinical outcome. All of the 39-bp and 18-bp deletion-type strains possessed the East Asian type cagA repeat region. The type II cag right-end junction genotype was predominant (84\%). The vacA $\mathrm{ml}$ genotype was significantly more common in strains isolated in Hanoi, where the incidence of gastric cancer is higher, than in strains from Ho Chi Minh.
\end{abstract}

Conclusion: Pre-EPIYA-region typing of the cagA gene could provide a new genetic marker of $H$. pylori genomic diversity. Our data support the hypothesis that vacA $\mathrm{ml}$ is closely associated with gastric carcinogenesis. 


\section{Background}

Helicobacter pylori is recognized to play a causative role in the pathogenesis of various gastroduodenal diseases including gastritis, peptic ulcer, gastric cancer and mucosa-associated lymphoid tissue (MALT) lymphoma [1-6]. However, only a minority of $H$. pylori-infected patients will develop severe manifestations, indicating that the clinical outcome is dependent on interactions between bacterial virulence, and host-related and environmental factors.

Gastric cancer is still a significant health problem in Asian countries. More than $56 \%$ of newly diagnosed gastric cancers arise in Asia, of which $42 \%$ are reported from China and $12 \%$ from Japan (data available at http://wwwdep.iarc.fr/). However the incidence of gastric cancer varies greatly, even among different regions of Asia. Based on the age-standardized incidence rate (ASR) of gastric cancer, Asian countries can be categorized as high-risk (e.g., Japan, Korea, China), intermediate-risk (e.g., Vietnam) or low-risk (e.g., Thailand and Indonesia). In contrast, the prevalence of $H$. pylori infection is similar among these countries, being relatively high in the elderly population $[7,8]$. Thus, although the association between $H$. pylori infection and the development of gastric cancer has been well established, it is still unclear why there is such a wide variation in the incidence of gastric cancer among Asian countries, an issue that has been referred to as the "Asian enigma" or "Asian paradox" [7,9].

Recent molecular epidemiologic data suggest that genetic diversity of $H$. pylori might be partly responsible for this phenomenon. A large number of studies have investigated the roles of putative virulence factors of $H$. pylori, the best studied being the cagA and $v a c A$ genes. The structure of the 3 ' repeat region of the cagA gene varies between strains from Western countries and those from East Asian countries [10-17]; East Asian type cagA strains are reported to be more virulent than their Western counterparts $[14,15]$.

H. pylori can be divided into five subtypes based on the structure of the right-end junction motif of the cag pathogenicity island (PAI), which can be a useful molecular marker for distinguishing isolates from different geographical areas [18]. Generally, type I is common in isolates from Western countries, type II in East Asian countries, and type III mainly in South Asia [18]. Types IV and $\mathrm{V}$ are relatively rare compared with the other types, but type $V$ has been found in a few strains from India and Thailand [12].

There is considerable variation in vacuolation activity among $H$. pylori strains $[19,20]$, primarily due to differences of vacA gene structure in the signal region (s1 and $\mathrm{s} 2$ ) and the middle region ( $\mathrm{m} 1$ and $\mathrm{m} 2)$ [21]. Among the $\mathrm{s} 1$ genotype, $\mathrm{s} 1 / \mathrm{m} 1$ is toxic for a wider range of epithelial cells than $\mathrm{s} 1 / \mathrm{m} 2$ [22]. The vacA s $2 / \mathrm{m} 2$ strains are virtually non-toxic [21] and are rarely associated with diseases [2325]. Importantly, most of the H. pylori strains isolated from countries with a high incidence of gastric cancer such as Japan and South Korea concurrently possess virulent genotypes such as vacA s1/m1 and East Asian type cagA $[13,14]$. In contrast, in countries with a low incidence of gastric cancer such as Thailand and India, a considerable proportion of $H$. pylori isolates have less virulent genotypes, such as vacA $\mathrm{m} 2$ and Western type cagA $[12,13]$.

Vietnam is located on the borderline between regions with high and low risk of gastric cancer. Interestingly, the ASR of gastric cancer in Vietnam was 21.8 in 2002, which is considered to be intermediate (i.e., lower than Japan [62.0], Korea [69.7] and China [41.4], but higher than Thailand [4.3] and Indonesia [3.5]) http://wwwdep.iarc.fr/. Moreover, despite the similarity in ethnicity and dietary factors, as well as the prevalence of $H$. pylori infection, the ASR of gastric cancer in the northern city of Hanoi is approximately 1.5 times higher than that in the southern city of Ho Chi Minh http://www-dep.iarc.fr/. We hypothesized that the $H$. pylori genotypes would differ between strains isolated from the two cities. Currently, however, there are few data about $H$. pylori genotypes isolated from Vietnam [26]. We therefore attempted to investigate several $H$. pylori genetic factors regarded as virulence or molecular epidemiologic markers in $H$. pylori isolates from Vietnam.

\section{Results}

\section{Patients and $\mathrm{H}$. pylori}

We recruited a total of 103 Vietnamese patients ( 47 males and 56 females), aged 14 to 83 years (mean age, 45 years), of whom 54 were from Hanoi and 49 were from Ho Chi Minh. Twenty-five patients were judged to have peptic ulcer disease (16 from Hanoi and 9 from Ho Chi Minh) and 78 had chronic gastritis ( 38 from Hanoi and 40 from Ho Chi Minh).

\section{Classification of the cagA gene according to the pre-EPIYA region}

We analyzed the sequences of the cagA Glu-Pro-Ile-Tyr-Ala (EPIYA) repeat region and upstream sequence of the EPIYA region of $H$. pylori isolated from Ho Chi Minh and Hanoi, located in the southern and northern parts of Vietnam, respectively. Except for five cases associated with cagA-negative strains, the EPIYA repeat region and preEPIYA region of the remaining 98 strains were successfully sequenced. The majority of Vietnamese strains (93\%; 94/ 103) had an East Asian type EPIYA repeat with three EPIYA motifs (i.e., ABD type based on the previous classi- 
fication $[15,27])$, and only 4 strains $(4 \%)$ had a Western type EPIYA repeat with three EPIYA motifs (i.e., ABC type) (Table 1).

Interestingly, about 300 bp upstream of the first EPIYA motif, we found that several strains carried a 39-bp or 18bp deletion (Figure 1). All strains with the 39-bp and 18bp deletion had an East Asian type EPIYA repeat and 4 of $5(80 \%)$ strains without the deletion had a Western type EPIYA repeat. Thus, the East Asian type was subdivisible into two groups according to the upstream sequence of the EPIYA repeat region: the 39-bp and 18-bp deletion types. Importantly, the majority of Vietnamese strains (77\%; 80/103) had the 18-bp deletion, irrespective of geographical location (80\% in Ho Chi Minh and 76\% in Hanoi) (Table 1). In contrast, only 13\% (13/103) of the isolates carried the 39-bp deletion. In this study, we designated the 18-bp deletion type as the Vietnamese preEPIYA type, and the 39-bp deletion type as the East Asian pre-EPIYA type. Three types of pre-EPIYA region were distinguishable by simple PCR (data not shown) using primer sets covering the cagA pre-EPIYA region, as described in Methods. However, there was no relationship between pre-EPIYA types and clinical outcome in this Vietnamese population (data not shown).

\section{Genotypes of the cag right-end junction}

It has been reported that the cag right-end junction motif can be classified into five groups [18]. We found that type II was the most common (84\%), followed by type I (9\%) and type III (4\%) (Table 1$)$. The remaining three strains could not be categorized into any genotype. This result was consistent with previous data showing that type II was the most common among $H$. pylori isolates from East Asian countries [13,18]. Interestingly, type I, which was considered to be specific for Western strains, was significantly more common in strains isolated in Ho Chi Minh $(16 \%)$ than in those originating from Hanoi $(2 \%)$ ( $\mathrm{p}<$ $0.05)$. In contrast, type II was significantly more common in Hanoi $(93 \%)$ than in Ho Chi Minh $(76 \%)(\mathrm{p}<0.05)$. There was no significant relationship between the cag right-end junction types and clinical outcome in this Vietnamese population (data not shown).

Type II was very common in $H$. pylori strains carried by Vietnamese (86\%: 69/80) and also in the East Asian preEPIYA type (100\%: 13/13) (Table 2). In contrast, among strains with a Western pre-EPIYA type, type II accounted for $40 \%$ (2/5) and type I for the remaining 60\% (3/5).

\section{Genotypes of the vacA genotypes}

All Vietnamese strains possessed the vacA s1 genotype and only one case from Hanoi possessed both the s1 and s2 genotypes, suggesting mixed infection with two strains. The $\mathrm{m} 1$ genotype was significantly more common in strains isolated in Hanoi than in those originating from Ho Chi Minh (54\% vs. 31\%) (p < 0.05) (Table 1).

The prevalence of the vacA $\mathrm{m} 1$ genotype was significantly higher in strains isolated from peptic ulcer patients $(60 \%$; $15 / 25)$ than in those from gastritis patients (37\%; 29/78) (odds ratios: 2.59, 95\% confidence interval: 1.006 .68 , $\mathrm{p}<$ $0.05)$. No significant relationship was observed between $m$ region genotypes and pre-EPIYA deletion types (Table 2).

\section{H. pylori genotypes and histology}

We examined whether the vacA genotypes and the cagA pre-EPIYA types were related to histological score. The five cagA-negative cases were excluded from histological anal-

Table I: Genotypes of cagA pre-EPIYA,cagA repeat, cag right-end junction and vacA of Vietnamese $H$. pylori strains.

\begin{tabular}{|c|c|c|c|c|}
\hline & & $\begin{array}{c}\text { Total } \\
(n=103)\end{array}$ & $\begin{array}{l}\text { Ho Chi Minh } \\
\quad(\mathrm{n}=49)\end{array}$ & $\begin{array}{l}\text { Hanoi } \\
(n=54)\end{array}$ \\
\hline \multirow[t]{3}{*}{ cagA pre-EPIYA } & Vietnamese pre-EPIYA type & 80 (77\%) & $39(80 \%)$ & $4 \mathrm{l}(76 \%)$ \\
\hline & East Asian pre-EPIYA type & $13(13 \%)$ & 4 (8\%) & $9(17 \%)$ \\
\hline & Western pre-EPIYA type & $5(5 \%)$ & $3(6 \%)$ & $2(4 \%)$ \\
\hline \multirow[t]{2}{*}{ cagA repeat } & East Asian type (ABD type) & $94(93 \%)$ & $43(88 \%)$ & $51(94 \%)$ \\
\hline & Western type (ABC type) & 4 (4\%) & $3(6 \%)$ & I (2\%) \\
\hline $\operatorname{cag} A(-)$ & & $5(5 \%)$ & $3(6 \%)$ & $2(4 \%)$ \\
\hline \multirow[t]{4}{*}{ cag right-end } & 1 & $9(9 \%)$ & $8(16 \%)$ & I (2\%) \\
\hline & II & $87(84 \%)$ & 37 (76\%) & $50(93 \%)$ \\
\hline & III & $4(4 \%)$ & $2(4 \%)$ & $2(4 \%)$ \\
\hline & N.D. & $3(3 \%)$ & $2(4 \%)$ & I (2\%) \\
\hline \multirow[t]{2}{*}{$\operatorname{vacA} \mathrm{s}^{*}$} & sl & $103(100 \%)$ & $49(100 \%)$ & $54(100 \%)$ \\
\hline & s2 & I (I\%) & $0(0 \%)$ & I (2\%) \\
\hline \multirow[t]{3}{*}{ vacA m† } & $\mathrm{ml}$ & $44(43 \%)$ & $15(31 \%)$ & $29(54 \%)$ \\
\hline & $\mathrm{m} 2$ & $54(52 \%)$ & $32(65 \%)$ & $22(41 \%)$ \\
\hline & N.D. & $5(5 \%)$ & $2(4 \%)$ & $3(6 \%)$ \\
\hline
\end{tabular}

N.D.: could not be determined.

* Both $\mathrm{s} 1$ and $\mathrm{s} 2$ were detected in one case.

$\dagger$ The prevalence of vacA $\mathrm{ml}$ is significantly higher in Hanoi than in Ho Chi Minh, $p<0.05$ 


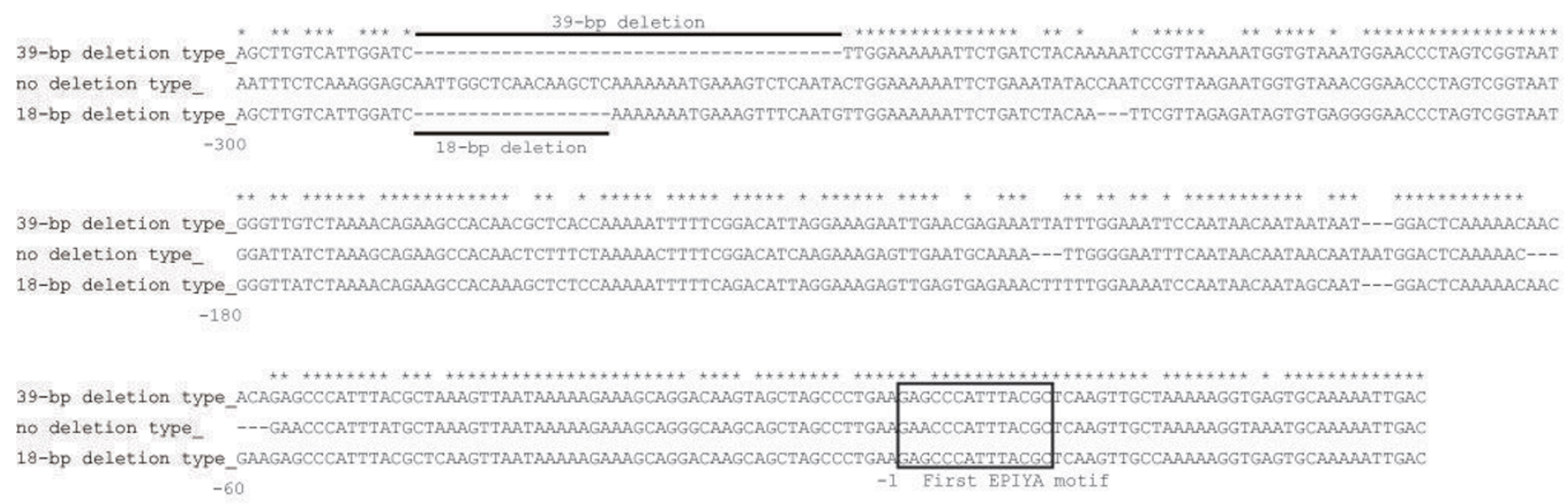

Figure I

Alignment of cagA pre-EPIYA region sequences from Vietnamese $\boldsymbol{H}$. pylori. An I8-bp deletion, a 39-bp deletion, and no deletion were found at about 300 bp upstream of the first EPIYA region. The first EPIYA sequence is indicated in the clear square. Numbers were input from the first EPIYA motif.

ysis. Univariate analysis showed that the antral mononuclear cell infiltration scores were significantly higher in tissue infected with Vietnamese or East Asian pre-EPIYA types than in those infected with the Western type (Table 3 ). The East Asian cagA repeat type was highly associated with severe mononuclear cell infiltration $(p<0.01)$ and the type III cag right-end junction was associated with mild neutrophil infiltration $(p<0.01)$ (Tables 3 and 4$)$. In contrast, there was no relationship between vacA middleregion genotypes and histological score (data not shown). There was no significant relationship between cagA genotypes and scores for atrophy and intestinal metaplasia (data not shown).

Multiple linear regression analysis was performed to determine which factor(s) was related to severity of histology. In the antrum, the cag end junction type III was significantly associated with milder neutrophil infiltration (partial regression coefficient $[\mathrm{PRC}] \pm \mathrm{SE}=-1.13 \pm 0.35$ compared with type I, $p<0.001)$ and more severe intestinal metaplasia $(0.61 \pm 0.27, p<0.05)$ (Table 5). The PRC of -1.13 for the cag end junction type III for neutrophil infiltration suggests that the neutrophil infiltration score associated with cag end junction type III strains would be expected to be 1.12 points lower than with type I strains. The Western pre-EPIYA type was significantly associated with milder antral neutrophil infiltration $(\mathrm{PRC} \pm \mathrm{SE}=-$ $0.66 \pm 0.29$ compared with the East Asian type, $p<0.01)$.

In the corpus and upper corpus, there were no significant differences between $H$. pylori genotypes and histological features, using either univariate analysis or multiple linear regression analysis (data not shown).

\section{Discussion}

In this study, we identified three types of deletion located upstream of the cagA 3' EPIYA repeat region: a 39-bp deletion, an 18-bp deletion, and lack of deletion. As of March, 2009, the GenBank database contained 326 cagA sequences of $H$. pylori that covered the pre-EPIYA region. Alignment of these sequences revealed that several strains carried a 39-bp or 18-bp deletion. As expected, the 39-bp deletion was present in most strains isolated from East Asia, but was absent in most strains from Western countries (Table 6). Moreover, all $19 \mathrm{cag} A$ sequences with a unique 18-bp deletion type were present in Asian strains (Table 6), suggesting that the deletion patterns might be applicable as markers of genomic diversity among Asian

Table 2: Relationship between cagA pre-EPIYA type and cag right-end junction types or vacA genotypes.

\begin{tabular}{|c|c|c|c|c|c|c|c|c|}
\hline & & \multicolumn{4}{|c|}{ cag right-end junction type } & \multicolumn{3}{|c|}{ vacA m type } \\
\hline & & 1 & II & III & N.D. & $\mathrm{ml}$ & $\mathrm{m} 2$ & $(-)$ \\
\hline \multirow[t]{4}{*}{ cagA pre-EPIYA type } & Vietnamese $(n=80)$ & 6 & 69 & 4 & I & 35 & 40 & 5 \\
\hline & East Asian $(n=13)$ & 0 & 13 & 0 & 0 & 6 & 7 & 0 \\
\hline & Western $(n=5)$ & 3 & 2 & 0 & 0 & 1 & 4 & 0 \\
\hline & $\operatorname{cag} A(-)(n=5)$ & 0 & 3 & 0 & 2 & 2 & 3 & 0 \\
\hline
\end{tabular}

N.D.: not determined 
Table 3: Histological scores of mononuclear cell infiltration in patients with chronic gastritis infected with $H$. pylori strains of different cagA genotypesin the antrum.

\begin{tabular}{|c|c|c|c|c|c|c|c|c|}
\hline \multirow[b]{3}{*}{ Grade } & \multicolumn{8}{|c|}{ Mononuclear cell infiltration } \\
\hline & \multicolumn{3}{|c|}{ pre-EPIYA typing } & \multicolumn{2}{|c|}{ EPIYA repeat typing } & \multicolumn{3}{|c|}{ cag right-end junction typing } \\
\hline & Vietnamese & $\begin{array}{c}\text { East } \\
\text { Asian }\end{array}$ & Western & $\begin{array}{c}\text { East } \\
\text { Asian }\end{array}$ & Western & 1 & II & III \\
\hline none & 0 & 0 & 0 & 0 & 0 & 0 & 0 & 0 \\
\hline mild & 24 & 5 & 5 & 31 & 4 & 5 & 28 & 2 \\
\hline moderate & 52 & 8 & 0 & 61 & 0 & 4 & 55 & 2 \\
\hline severe & 4 & 0 & 0 & 4 & 0 & 0 & 4 & 0 \\
\hline$p$-value & $* p$ & $* * p$ & & & & & N.S. & \\
\hline
\end{tabular}

Mann-Whitney rank sum test. N.S.: not significant.

$* p<0.01 ; * * p<0.05 ;$ vs. Western type

$* * * p<0.01$

H. pylori isolates. Although the 18-bp deletion type appears to be specific to Asian strains, the precise distribution was unclear because of the small number of cases examined. Among four Vietnamese cagA sequences deposited in GenBank, three had the 18-bp deletion type and one had the 39-bp deletion type (Table 6), suggesting that the 18-bp deletion type might be common in Vietnamese strains. GenBank data showed that the 18-bp deletion type also seemed to be common in Hong Kong and Thailand, in addition to Vietnam. However, our preliminary data showed that the prevalence of strains with the 18-bp deletion type was less than $10 \%$ in both Hong Kong and Thailand (our unpublished data). These data suggest that the 18-bp deletion type could be applicable as a new marker for Vietnamese H. pylori strains.

Through an extensive search of the Genbank database in combination with our data, we showed that these types, which were designated as the Western, East Asian and
Vietnamese pre-EPIYA types, appear to be specific for each corresponding geographic region, and thus could be applicable as a new genetic marker for the genomic diversity of $H$. pylori. Interestingly, there was a close relationship between the cagA repeat region genotypes and the pre-EPIYA type. The great majority of the East Asian cagA repeat region type contained either the East Asian or Vietnamese pre-EPIYA type, whereas almost all of the Western cagA repeat region type had the Western pre-EPIYA type. Vietnamese strains could not be distinguished from other East Asian strains on the basis of previous genotyping including the cagA repeat region genotypes. In contrast, the novel pre-EPIYA types were able to distinguish Vietnamese strains from other East Asian strains with high sensitivity and specificity (e.g., sensitivity of $81.6 \%$ and specificity of $96.9 \%$ when the 98 cagA-positive Vietnamese strains in this study were compared with 162 Japanese strains deposited in GenBank). Therefore, this novel system will be useful for epidemiological studies of the dis-

Table 4: Histological scores of neutrophil infiltration in patients with chronic gastritis infected with $H$. pylori strains of different cagA genotypes in the antrum.

\begin{tabular}{|c|c|c|c|c|c|c|c|c|}
\hline \multirow[b]{3}{*}{ Grade } & \multicolumn{8}{|c|}{ Neutrophil infiltration } \\
\hline & \multicolumn{3}{|c|}{ pre-EPIYA typing } & \multicolumn{2}{|c|}{ EPIYA repeat typing } & \multicolumn{3}{|c|}{ cag right-end junction typing } \\
\hline & Vietnamese & $\begin{array}{c}\text { East } \\
\text { Asian }\end{array}$ & Western & $\begin{array}{c}\text { East } \\
\text { Asian }\end{array}$ & Western & 1 & II & III \\
\hline none & 4 & 1 & I & 7 & 0 & 0 & 4 & 3 \\
\hline mild & 49 & 9 & 4 & 59 & 4 & 6 & 56 & 1 \\
\hline moderate & 26 & 3 & 0 & 29 & 0 & 3 & 26 & 0 \\
\hline severe & 1 & 0 & 0 & 1 & 0 & 0 & 1 & 0 \\
\hline$p$-value & & N.S. & & & & $* * p$ & $* p$ & \\
\hline
\end{tabular}

Mann-Whitney rank sum test. N.S.: not significant.

$*_{p}<0.01 ; *_{p}<0.05$; vs. type III 
Table 5: Multiple linear regression analysis of the severity of histology in the antrum.

\begin{tabular}{|c|c|c|c|c|c|}
\hline & Types & Control & Case & $\mathrm{PRC} \pm \mathrm{SE}$ & $p$ value \\
\hline \multirow[t]{4}{*}{ Neutrophil infiltration } & cag right-end junction & type I & type II & $0.017 \pm 0.25$ & $<0.001$ \\
\hline & & & type III & $-1.13 \pm 0.35$ & \\
\hline & cagA pre-EPIYA & East Asian & Western & $-0.35 \pm 0.30$ & 0.08 \\
\hline & & & Vietnamese & $0.19 \pm 0.16$ & \\
\hline \multirow[t]{3}{*}{ Mononuclear cell infiltration } & cagA pre-EPIYA & East Asian & Western & $-0.66 \pm 0.29$ & 0.008 \\
\hline & & & Vietnamese & $0.13 \pm 0.15$ & \\
\hline & vacA m & $\mathrm{m} 2$ & $\mathrm{ml}$ & $-0.20 \pm 0.11$ & 0.07 \\
\hline Atrophy & none & & & & \\
\hline \multirow[t]{2}{*}{ Intestinal metaplasia } & cag right-end junction & type I & type II & $0.02 \pm 0.17$ & 0.03 \\
\hline & & & type III & $0.61 \pm 0.27$ & \\
\hline
\end{tabular}

PRC: partial regression coefficient

tribution of Vietnamese strains. Notably, the Vietnamese pre-EPIYA type is predominant in Vietnam, where the incidence of gastric cancer is lower than in other East Asian countries such as Japan and South Korea, suggesting that the pre-EPIYA region might have some biological functions that partly contribute to the differences in incidence of gastric cancer, although we were unable to find any differences in the prevalence of peptic ulcer disease and histological findings between East Asian and Vietnamese pre-EPIYA types in this study. Further studies will be necessary to investigate the function of the pre-EPIYA region.

On the basis of structure, the cag right-end junction is classifiable into five subtypes [18]. Generally, type I is common in isolates from Western countries, type II in East

Table 6: Pre-EPIYA region patterns deposited in GenBank.

\begin{tabular}{lcccc}
\hline County & Total & 39-bp deletion & No deletion & I8-bp deletion \\
\hline Japan & 181 & $145(80 \%)$ & $31(17 \%)$ & $5(3 \%)$ \\
China & 37 & $33(89 \%)$ & I (3\%) & $3(8 \%)$ \\
Korea & 8 & $5(63 \%)$ & $3(38 \%)$ & 0 \\
Hong Kong & 8 & $4(50 \%)$ & 0 & $4(50 \%)$ \\
Taiwan & 5 & $4(80 \%)$ & 0 & $1(20 \%)$ \\
Thailand & 5 & 0 & $2(40 \%)$ & $3(60 \%)$ \\
Vietnam & 4 & $1(25 \%)$ & 0 & $3(75 \%)$ \\
Sweden & 16 & 0 & $16(100 \%)$ & 0 \\
Colombia & 14 & 0 & $14(100 \%)$ & 0 \\
USA & 13 & 0 & $13(100 \%)$ & 0 \\
Italy & 11 & 0 & $11(100 \%)$ & 0 \\
Iran & 8 & 0 & $8(100 \%)$ & 0 \\
India & 6 & 0 & $6(100 \%)$ & 0 \\
Kazakhstan & 3 & 0 & $3(100 \%)$ & 0 \\
Germany & 3 & 0 & $3(100 \%)$ & 0 \\
Chile & 1 & 0 & $1(100 \%)$ & 0 \\
Austria & 1 & 0 & $1(100 \%)$ & 0 \\
Australia & 1 & 0 & $1(100 \%)$ & 0 \\
non-East Asia & 1 & 0 & $1(100 \%)$ & 0 \\
\hline Total & 326 & $192(59 \%)$ & $115(35 \%)$ & $19(6 \%)$ \\
\hline
\end{tabular}

Asian countries, and type III mainly in South Asia [18]. In agreement with previous data $[12,13,18]$, the majority of Vietnamese strains we studied were type II strains. Interestingly, $16 \%$ of strains isolated in Ho Chi Minh possessed type I, which was a much higher prevalence than in other East Asian strains (e.g., none of 449 strains from Japan, Korea, Taiwan or Hong Kong possessed type I in a previous study [13]). This might explain the relatively higher frequencies of East Asian-type cagA amongst Hanoi isolates (e.g. East Asian pre-EPIYA and cagA repeat types), and hence the higher incidence of gastric cancer in that population. However, the reason for the high prevalence of type I in Ho Chi Minh is currently unknown. There is no evidence for a greater level of interracial mixing with Europeans in Ho Chi Minh than in Hanoi, particularly during the latter half of the 20th century. Extensive surveys will be necessary to elucidate the geographical distribution in East Asian countries. Interestingly, histological data from the antrum showed that the cag end junction type III was significantly associated with mild neutrophil infiltration and severe intestinal metaplasia. This is the first study to have demonstrated a relationship between cag end junction type and histological features; however the number of type III strains in this study was very small $(n=4)$ and further work will be necessary to clarify the importance of type III genotypes in countries where the prevalence of type III is high (e.g., South Asia).

The multifactorial model of gastric malignant transformation is currently accepted, and not only $H$. pylori virulence factors, but also other factors such as host genetic susceptibility and environmental factors will undoubtedly play certain roles. In Vietnam, the incidence of gastric cancer in the northern city of Hanoi is reported to be 1.5 times higher than that in the southern city of Ho Chi Minh. Importantly, the two cities share a lot of similarity in terms of ethnicity, living standards, lifestyle and dietary habits. Therefore, these two cities can serve as a good model for understanding the role $H$. pylori virulence factors in the development of gastric cancer. In this study, the 
prevalence of the vacA $\mathrm{m} 1$ type, which is currently considered to be more toxic and more closely associated with the development of gastric cancer than the m2 type, was significantly higher in strains isolated in Hanoi than those originating from Ho Chi Minh. Interestingly, compared with other East Asian countries such as Japan and Korea, where the incidence of gastric cancer is high, the prevalence of the vacA $\mathrm{m} 1$ type in Vietnam is much lower [13]. Taken together, our data support the hypothesis that the vacA $\mathrm{m} 1$ genotype is closely associated with gastric carcinogenesis and may provide a partial explanation for the Asian paradox. In addition, we have also found that the vacA $\mathrm{m} 1$ genotype was related to the development of peptic ulcers in the Vietnamese population. Although we failed to obtain evidence that $\mathrm{m} 1$ strains induced more severe gastric injury in terms of histology, our current data support the hypothesis that $\mathrm{m} 1$ strains are more toxic than $\mathrm{m} 2$ strains, and that the $\mathrm{m} 1$ genotype play a major role in countries where other factors are relatively homogeneous. Overall, we propose that examination of H. pylori genotypes in strains isolated from two cities in Vietnam, Ho Chi Minh and Hanoi, would be useful for investigating the roles of $H$. pylori-related factors in the pathogenesis of gastroduodenal disease.

\section{Conclusion}

We have found three types of deletion in the pre-EPIYA region of the cagA gene: a 39-bp deletion, an 18-bp deletion, and no deletion, and demonstrated that the cagA genotype could be applicable as a new genetic marker of genomic diversity in $H$. pylori. In fact, the 18-bp deletion type appeared to be a marker of Vietnamese $H$. pylori. Comparison of two geographically distant cities in Vietnam, Hanoi and Ho Chi Minh, showed that the vacA $\mathrm{m} 1$ genotype, thought to be more toxic than the vacA $\mathrm{m} 2$ type, is more prevalent in Hanoi, where the incidence of gastric cancer is higher than in Ho Chi Minh. Our data support the hypothesis that the vacA $\mathrm{m} 1$ type is closely associated with gastric carcinogenesis.

\section{Methods}

\section{Patients and $\mathbf{H}$. pylori}

H. pylori strains were obtained from the gastric mucosa of H. pylori-infected patients who underwent endoscopy at 108 Hospital, Hanoi, and Cho Ray Hospital, Ho Chi Minh. The biopsy specimens were immediately placed in Portagerm pylori (BioMérieux, Nürtingen, Germany)[28] at $4{ }^{\circ} \mathrm{C}$ and then sent to Oita University, Oita, Japan. $H$. pylori was cultured as described previously [14]. Informed consent was obtained from all participants and the protocol was approved by the local hospital ethics committees. Patients with a history of partial gastric resection, $H$. pylori eradication therapy or treatment with antibiotics, bismuth-containing compounds, H2-receptor blockers or proton pump inhibitors within 4 weeks prior to the study were excluded.

\section{H. pylori genotyping}

For DNA extraction, multiple colonies on blood agar plates were harvested together, and bacterial genomic DNA was extracted according to the CTAB (hexadecyltrimethylammonium bromide) method [29] and subsequently suspended in TE buffer $(10 \mathrm{mM}$ Tris $\mathrm{HCl}$ and 1 mM EDTA). A DNA fragment covering approximately 300 bp upstream from the first EPIYA motif in the cagA 3' repeat region, which we designated the pre-EPIYA region in this study, was amplified by PCR using the following primer sets: T5: 5'-AAG CGT TAG CCG ATC TCA AA-3' (forward), and 1-AS: 5'-CAT TAC CGA CTA GGG TTC C3' (reverse) [27]. The amplified DNA fragments were separated by electrophoresis on $2 \%$ agarose gel, stained with ethidium bromide, and finally visualized under ultraviolet light.

For sequencing of the pre-repeat region of the cagA gene, a DNA fragment of approximately 1,100 bp covering both the pre- EPIYA region and repeat region was initially amplified by PCR using the following primer sets: 2059f: 5'-GAA TTG TCT GAT AAA CTT G-3' (forward), and 3156r: 5'-GCG TAT GTG GCT GTT AGT AGC G-3' (reverse), then the amplified DNA fragments were sequenced with an ABI Prism 310 Genetic Analyzer [27] (Applied Biosystems, CA) in accordance with the manufacturer's instructions. Multiple sequence alignments of the cagA pre-EPIYA sequences were generated using the ClustalX programs (downloaded from ftp://ftp.ebi.ac.uk/ pub/software/clustalw2).

The vacA genotyping (signal regions $s 1$ and $s 2$, and middle regions $\mathrm{m} 1$ and $\mathrm{m} 2$ ) and cag right-junction motif genotyping (type I to $\mathrm{V}$ ) were performed as described previously $[11,18,21]$.

\section{Dot blot analysis}

To confirm the cagA negative status, dot blot analysis was performed as described previously[30]. Briefly, $200 \mathrm{ng}$ of each sample DNA was mixed with denaturing buffer and spotted onto a Hybond $\mathrm{N}^{+}$membrane (Amersham Biosciences, Buckinghamshire, UK) using a 96-well Bio-Dot apparatus (Bio-Rad, Ivry-sur-Seine, France). DNA of the reference strain ATCC43504 and human DNA were also transferred to the membrane as positive and negative controls, respectively. The cagA of strain ATCC43504 was amplified by PCR with the above-mentioned primer sets. The amplified fragments were purified with an Illustra GFX PCR DNA and Gel Band Purification Kit and used as probes. The probes were labeled with horseradish peroxidase, hybridized to the membranes overnight at $42^{\circ} \mathrm{C}$, 
and finally exposed to Hyperfilm ECL using ECL Direct Nucleic Acid Labeling and Detection Systems (Amersham Biosciences, Buckinghamshire, UK).

\section{Histological analysis}

Three biopsy specimens from the antrum, corpus and upper part of the lesser curvature were used for histological examination. The biopsy specimens were fixed in 10\% buffered formalin, and thinly sliced sections were stained with hematoxylin and eosin (H\&E) and Giemsa. Histological features of neutrophil infiltration, mononuclear cell infiltration, grade of atrophy and grade of intestinal metaplasia were scored into four grades in accordance with the Updated Sydney system (0: none, 1: mild, 2: moderate, 3: severe) [31].

\section{Statistical analysis}

Statistical analysis of the distribution of $H$. pylori genotypes was performed using Fisher's exact test. The MannWhitney rank sum test was used for assessing differences between ordered categories such as histological grade. The effects of the $H$. pylori genotypes on the risk for developing peptic ulcer in patients were expressed as odds ratios with 95\% confidence intervals with reference to subjects with gastritis. Multiple linear regression analysis was performed to determine which factor(s) was related to the severity of histology, where age, sex, bacterial factors and clinical outcome were explanatory variables. Variables were selected by backward stepwise deletion in the logistic regression and by the F-out and F-in stepwise method in the linear regression, where F values were both 2.0. Differences at $P<0.05$ were accepted as statistically significant. Calculations were carried out using the statistical software package "JMP IN(R) 5.1J" (SAS Institute, Cary, NC) or "HALBAU" (Gendai Sugaku-sha, Kyoto, Japan).

Nucleotide sequence data reported are available under the DDBJ accession numbers $\underline{A B 469377}$, and $\underline{A B 469561}$ to $\underline{\mathrm{AB} 469657 .}$.

\section{Authors' contributions}

TU participated in the design of the study, carried out the experiments and drafted the manuscript. LTN and AT carried out the PCR experiments and statistical analysis. TM, TDT and LT arranged the patients and performed endoscopy in Hanoi. DQDH, HHH and TO arranged the patients and performed endoscopy in Ho Chi Minh. MK, KM and TK participated in the discussion of the study design. TF, MM and YY designed the study. All authors have read and approved the final manuscript.

\section{Acknowledgements}

This work was supported in part by Grants-in-Aid from the Japan Society for the Promotion of Science (20790285). This work was also supported in part by the Office of Research and Development, Medical Research Service Department of Veterans Affairs, and by a Public Health Service grant
DK56338, which funds the Texas Medical Center Digestive Diseases Center. The project described was also supported by Grant Number DK 62813 from the NIH. Their contents were the sole responsibility of the authors, and did not necessarily represent the official views of the VA or $\mathrm{NIH}$.

\section{References}

I. Hopkins RJ, Girardi LS, Turney EA: Relationship between Helicobacter pylori eradication and reduced duodenal and gastric ulcer recurrence: a review. Gastroenterology 1996, I I 0(4): | 244- I 252.

2. Kuipers EJ, Perez-Perez GI, Meuwissen SG, Blaser MJ: Helicobacter pylori and atrophic gastritis: importance of the cagA status. J Natl Cancer Inst 1995, 87(23): I777-I780.

3. Parsonnet J, Friedman GD, Vandersteen DP, Chang Y, Vogelman JH, Orentreich N, Sibley RK: Helicobacter pylori infection and the risk of gastric carcinoma. N EnglJ Med I99|, 325( I6): I I 27-I I 3 I.

4. Forman D, Newell DG, Fullerton F, Yarnell JW, Stacey AR, Wald N, Sitas F: Association between infection with Helicobacter pylori and risk of gastric cancer: evidence from a prospective investigation. Bmj I99|, 302(6788): I302-I305.

5. The EUROGAST Study Group: An international association between Helicobacter pylori infection and gastric cancer. Lancet I993, 34I(8857): I 359-I362.

6. Wotherspoon AC: A critical review of the effect of Helicobacter pylori eradication on gastric MALT Iymphoma. Current gastroenterology reports 2000, 2(6):494-498.

7. Miwa H, Go MF, Sato N: H. pylori and gastric cancer: the Asian enigma. The American journal of gastroenterology 2002, 97(5): I 106-III2.

8. Asaka M, Kimura T, Kudo M, Takeda H, Mitani S, Miyazaki T, Miki K, Graham DY: Relationship of Helicobacter pylori to serum pepsinogens in an asymptomatic Japanese population. Gastroenterology 1992, 102(3):760-766.

9. Singh K, Ghoshal UC: Causal role of Helicobacter pylori infection in gastric cancer: an Asian enigma. World J Gastroenterol 2006, I 2(9): |346-135|.

10. Basso D, Zambon CF, Letley DP, Stranges A, Marchet A, Rhead JL, Schiavon S, Guariso G, Ceroti M, Nitti D, et al.: Clinical relevance of Helicobacter pylori cagA and vacA gene polymorphisms. Gastroenterology 2008, I35(I):91-99.

II. Yamaoka Y, El-Zimaity HM, Gutierrez O, Figura N, Kim JG, Kodama T, Kashima K, Graham DY: Relationship between the cagA 3' repeat region of Helicobacter pylori, gastric histology, and susceptibility to low pH. Gastroenterology I999, I I 7(2):342-349.

12. Vilaichone RK, Mahachai V, Tumwasorn S, Wu JY, Graham DY, Yamaoka Y: Molecular epidemiology and outcome of Helicobacter pylori infection in Thailand: a cultural cross roads. Helicobacter 2004, 9(5):453-459.

13. Yamaoka Y, Orito E, Mizokami M, Gutierrez O, Saitou N, Kodama T, Osato MS, Kim JG, Ramirez FC, Mahachai V, et al:: Helicobacter pylori in North and South America before Columbus. FEBS letters 2002, 5 I 7(13): 180- I84.

14. Azuma T, Yamazaki S, Yamakawa A, Ohtani M, Muramatsu A, Suto H, Ito $\mathrm{Y}$, Dojo $\mathrm{M}$, Yamazaki $\mathrm{Y}$, Kuriyama $M$, et al:: Association between diversity in the Src homology 2 domain containing tyrosine phosphatase binding site of Helicobacter pylori CagA protein and gastric atrophy and cancer. J Infect Dis 2004, I 89(5):820-827.

15. Hatakeyama M: Oncogenic mechanisms of the Helicobacter pylori CagA protein. Nat Rev Cancer 2004, 4(9):688-694.

16. Yamaoka Y, Kodama T, Kashima K, Graham DY, Sepulveda AR: Variants of the 3' region of the cagA gene in Helicobacter pylori isolates from patients with different $H$. pylori-associated diseases. Journal of clinical microbiology 1998, 36(8):2258-2263.

17. Yamaoka Y, Osato MS, Sepulveda AR, Gutierrez O, Figura N, Kim JG, Kodama T, Kashima K, Graham DY: Molecular epidemiology of Helicobacter pylori : separation of $H$. pylori from East Asian and non-Asian countries. Epidemiology and infection 2000, I 24( I):91-96.

18. Kersulyte D, Mukhopadhyay AK, Velapatino B, Su W, Pan Z, Garcia C, Hernandez V, Valdez Y, Mistry RS, Gilman RH, et al.: Differences in genotypes of Helicobacter pylori from different human populations. Journal of bacteriology 2000, I 82(I I):32 I0-32 I 8. 
19. Cover TL, Blaser MJ: Purification and characterization of the vacuolating toxin from Helicobacter pylori. J Biol Chem 1992, 267(15): 10570-10575.

20. Leunk RD: Production of a cytotoxin by Helicobacter pylori. Reviews of infectious diseases I991, I3(Suppl 8):S686-689.

21. Atherton JC, Cao P, Peek RM Jr, Tummuru MK, Blaser MJ, Cover TL: Mosaicism in vacuolating cytotoxin alleles of Helicobacter pylori. Association of specific vacA types with cytotoxin production and peptic ulceration. I Biol Chem 1995 270(30): $1777|-| 7777$.

22. Letley DP, Rhead JL, Twells RJ, Dove B, Atherton JC: Determinants of non-toxicity in the gastric pathogen Helicobacter pylori. J Biol Chem 2003, 278(29):26734-2674I.

23. Atherton JC, Peek RM Jr, Tham KT, Cover TL, Blaser MJ: Clinical and pathological importance of heterogeneity in vacA, the vacuolating cytotoxin gene of Helicobacter pylori. Gastroenterology 1997, I I 2(I):92-99.

24. Van Doorn LJ, Figueiredo C, Megraud F, Pena S, Midolo P, Queiroz DM, Carneiro F, Vanderborght B, Pegado MD, Sanna R, et al.: Geographic distribution of vacA allelic types of Helicobacter pylori. Gastroenterology 1999, I 16(4):823-830.

25. Atherton JC: The pathogenesis of Helicobacter pylori -induced gastro-duodenal diseases. Annual review of pathology 2006, I:63-96.

26. Matsuhisa TM, Yamada NY, Kato SK, Matsukura NM: Helicobacter pylori infection, mucosal atrophy and intestinal metaplasia in Asian populations: a comparative study in age-, gender- and endoscopic diagnosis-matched subjects. Helicobacter 2003, 8(I):29-35.

27. Uchida T, Kanada R, Tsukamoto Y, Hijiya N, Matsuura K, Yano S, Yokoyama S, Kishida T, Kodama M, Murakami K, et al.: Immunohistochemical diagnosis of the cagA -gene genotype of Helicobacter pylori with anti-East Asian CagA-specific antibody. Cancer science 2007, 98(4):52I-528.

28. Heep M, Scheibl K, Degrell A, Lehn N: Transport and storage of fresh and frozen gastric biopsy specimens for optimal recovery of Helicobacter pylori. Journal of clinical microbiology 1999 , 37(II):3764-3766.

29. Wilson K: Preparation of genomic DNA from bacteria, UNIT2.4. Volume I. New York: John Wiley \& Sons; 1999.

30. Occhialini A, Marais A, Alm R, Garcia F, Sierra R, Megraud F: Distribution of open reading frames of plasticity region of strain $\mathbf{J 9 9}$ in Helicobacter pylori strains isolated from gastric carcinoma and gastritis patients in Costa Rica. Infection and immunity 2000, 68(I I):6240-6249.

31. Dixon MF, Genta RM, Yardley JH, Correa P: Classification and grading of gastritis. The updated Sydney System. International Workshop on the Histopathology of Gastritis, Houston 1994. The American journal of surgical pathology 1996, 20(10): $|16|-|| 8 \mid$.
Publish with Bio Med Central and every scientist can read your work free of charge

"BioMed Central will be the most significant development for disseminating the results of biomedical research in our lifetime. "

Sir Paul Nurse, Cancer Research UK

Your research papers will be:

- available free of charge to the entire biomedical community

- peer reviewed and published immediately upon acceptance

- cited in PubMed and archived on PubMed Central

- yours - you keep the copyright
BioMedcentral 